\title{
Contribution fuel consumption of fishing vessel operation to greenhouse gas emission
}

\begin{abstract}
Fishing vessel operation highly depends on fossil fuels such as gasoline, diesel to generate power. Combustion of fossil fuel would generate greenhouse gas emission such as carbon dioxide. However, the estimation of carbon dioxide emission from fishing vessel is rather scarce in Malaysia. This paper describes carbon dioxide emission estimation from fishing vessels operation in Selangor. This study was conducted at four fisheries districts in Selangor where fishing vessels anchored for operation. Fishing operation activities were divided into four fisheries operation zones (A, B, C, and C2). It involved 3,252 fishing vessels. Firstly, carbon dioxide emission for each vessel is determined by using tier 1 method waterborne navigation equation provided from Chapter 3 mobile combustion, volume two Energy, 2006 IPCC Guidelines for National Greenhouse Gas Emission Inventory. After the carbon dioxide emission estimation was calculated, an inventory of emission was carried out. Then, ANOVA test was used to determine the significant differences between fishing gear and fisheries zones. Total carbon dioxide emission from fishing vessels operation in Selangor is $295.44 \mathrm{Gg}$ CO2 for 2012. ANOVA test indicated there is difference in the mean carbon dioxide emission estimation between different types of fishing gear. There are also significant differences in the mean carbon dioxide emission estimation from four different fisheries zones in Selangor. Turkey Kramer Multiple Comparisons was applied to determine the pair of carbon dioxide emission of fishing vessels between types of fishing gears and fisheries zones. The burning of $89.35 \mathrm{Gg}$ of fossil fuel by fishing operation released $295.4 \mathrm{Gg}$ in 2012 . Total amount of carbon dioxide emission from fishing vessel is low compare to latest Malaysia total carbon dioxide emission in 2000, 222,990 Gg CO2. In conclusion, status of carbon dioxide emission by fishing vessel operation has been determined for Selangor.
\end{abstract}

Keyword: Carbon dioxide emission; Fuel consumption; Fishing vessel operation 